\title{
Clinical symptoms associated with seroconversion for HIV-1 among misusers of intravenous drugs: comparison with homosexual seroconverters and infected and non-infected intravenous drug misusers
}

\author{
G H C Mientjes, E J C van Ameijden, H M Weigel, J A R van den Hoek, R A Coutinho
}

\begin{abstract}
Objective-To study the clinical symptoms associated with seroconversion for HIV-1 among misusers of intravenous drugs.

Design-Case-control study in cohorts of drug misusers and homosexual men.

Setting-Outpatient clinic, Municipal Health Service, Amsterdam.

Subjects-Misusers of intravenous drugs from our prospective cohort who seroconverted for HIV. Controls were drug users positive for HIV, drug users negative for HIV, and homosexual men who had seroconverted.
\end{abstract}

Results-Five out of $18(28 \%)$ drug users were admitted to hospital with bacterial pneumonia in the four to six months between their last visit at which they were HIV negative and their first visit when they were HIV positive. For comparison none of the 27 homosexual men who seroconverted for HIV, three out of $177(2 \%)$ drug users negative for HIV, and 10 out of $112(9 \%)$ drug users positive for HIV reported bacterial pneumonia. One out of the 18 drug users who seroconverted suffered from oesophageal candidiasis at the time of seroconversion. Other clinical symptoms did not differ between drug users who seroconverted and those who remained negative for HIV, probably due to the high background morbidity among the drug users.

Conclusions-Seroconversion to HIV-1 among intravenous drug misusers is associated with bacterial pneumonia. Those drug users with previously negative test results for HIV who are admitted to hospital for bacterial pneumonia should be tested to detect primary infection with HIV-1.

Municipal Health Service, Department of Public Health and Environment, Amsterdam, The Netherlands G H C Mientjes, physician E J C van Ameijden, epidemiologist

JA R van den Hoek, coordinator AIDS research projects

R A Coutinho, professor of epidemiology

\section{Hospital 'Onze Lieve} Vrouwe Gasthuis', Amsterdam, The

Netherlands

H M Weigel, senior physician

Correspondence to: Dr Mientjes, Municipal Health Service, Department of Public Health and Environment, PO Box 20244, $1000 \mathrm{HE}$ Amsterdam,

The Netherlands

$B M F 1993 ; 306: 371-3$

\section{Introduction}

Primary infection with HIV-1 may cause an acute viral syndrome with symptoms varying from mild fever, malaise, headaches, and maculopapular rash to more severe symptoms like aseptic meningoencephalitis and even oesophageal candidiasis. ${ }^{1-3}$ In general symptoms are mild and admission to hospital is necessary in only a few cases. Most reports describe primary HIV-1 infection among groups other than misusers of intravenous drugs. This group differs from other groups at risk of infection with HIV, like homosexual men and men with haemophilia, as their lifestyle often causes a high background incidence of disease and disease may be camouflaged by the use of illegal drugs. The incidence of bacterial infections such as endocarditis and pneumonia is higher regardless of HIV infection than in other groups at risk. ${ }^{4-6}$ In addition, immunological disturbances due to frequent injecting among drug users negative for HIV have been reported. ${ }^{7}$ We therefore performed a study to see whether the clinical manifestations associated with seroconversion for HIV-1 among intravenous drug misusers differed from those described in other groups at risk.

\section{Subjects and methods}

Participants of the follow up study among drug users in Amsterdam have been recruited since December $1985 .^{8}$ All participants were interviewed by using a standard questionnaire and were asked to return for follow up examination every four months. From April 1989 all participants, positive and negative for HIV, underwent physical examination and, in addition to serological tests, immunological tests were performed routinely at each visit.

As the purpose of the present analysis was to study the clinical and immunological manifestations accompanying seroconversion for HIV-1 antibody among intravenous drug users, we selected only drug users who seroconverted in the period April 1989 to December 1991. Subjects were eligible when the period between the last test result negative for HIV and the first test result positive for HIV-1 was no longer than six months. As controls we selected drug users negative and positive for HIV from our cohort and randomly selected one visit of each drug user. Subjects with follow up visits in the period April 1989 to December 1991 were eligible. The period between the selected control visit and the previous visit had to be less than six months. Visits from drug users who were positive for HIV and had AIDS were not eligible.

To compare seroconversion for HIV between drug users and homosexual men an additional control group of seroconverters for HIV-1 was selected from our cohort of homosexual men in Amsterdam, which has been extensively described. ${ }^{9}$ This cohort was started in 1984. The organisation of the cohort of homosexual men was the same as for the cohort of drug users, and all serological and immunological tests were performed in the same laboratories. Participants returned for follow up every three to six months. From this cohort we selected homosexual men who seroconverted in the same study period as the drug users who seroconverted. Immunological tests were not performed on homosexual men negative for HIV after September 1987. Therefore immunological data for the homosexual men were not available at the visit preceding seroconversion.

HIV antibodies were detected with enzyme linked immunosorbent assay (ELISA), confirmation was performed with competitive ELISA or western blotting, or both. ${ }^{7}$ Lymphocyte immunophenotyping was performed with a fluorescent activated cell sorter scanner (Becton and Dickinson); whole blood lymphocyte culture is described in detail elsewhere. ${ }^{710}$

Statistical analysis was performed with $\chi^{2}$ and Student's $t$ tests. When expected cell frequencies were less than 5 Fisher's exact test was used. In case of non-normal distribution the non-parametric MannWhitney $U$ test was performed. A p value of $\leqslant 0.05$ was chosen as significant. Logistic regression models were used to determine which variables significantly and independently could predict bacterial pneumonia and to adjust for potential confounders. A significance level 
of $p \leqslant 0.05$ according to the likelihood ratio statistics was chosen for entry in the model. (All analyses were performed with the SPSS/PC+ statistical package.)

\section{Results}

In the study period 18 intravenous drug misusers who met all criteria seroconverted for HIV-1. The mean time since their last visit when they were negative for HIV was 129 days. The visits (referred to as index visits) of 177 drug users negative for HIV-1 and 112 drug users positive for HIV-1 were randomly selected from the cohort to serve as controls. In the cohort of homosexual men 27 seroconverted in the study period; the mean time since their last visit when they were negative for HIV was 165 days. Table I shows the general characteristics of the drug users who seroconverted, the drug users positive for HIV, the drug users negative for HIV, and the homosexual men who seroconverted. Table II compares the clinical symptoms of the 18 drug users who seroconverted, the 177 control drug users who were negative for HIV, and the 27 homosexual men who seroconverted. Minor

TABLE I-General characteristics of intravenous drug misusers and homosexual men and their HIV state

\begin{tabular}{|c|c|c|c|c|}
\hline & $\begin{array}{c}\text { Intravenous } \\
\text { drug users who } \\
\text { seroconverted } \\
\text { for HIV } \\
(n=18)\end{array}$ & $\begin{array}{c}\text { Intravenous } \\
\text { drug users } \\
\text { positive for } \\
\text { HIV } \\
(n=122)\end{array}$ & $\begin{array}{c}\text { Intravenous } \\
\text { drug users } \\
\text { negative for } \\
\text { HIV } \\
(n=177)\end{array}$ & $\begin{array}{c}\text { Homosexual } \\
\text { men who } \\
\text { seroconverted } \\
\text { for HIV } \\
(n=27)\end{array}$ \\
\hline Mean (SD) age (years) & $31 \cdot 2(5 \cdot 4)^{\star}$ & $33 \cdot 0(5 \cdot 7)$ & $31.9(6.0)$ & $38 \cdot 0(7.5)^{\star}$ \\
\hline No of men & & 65 & 103 & $27^{\star}$ \\
\hline Mean (SD) time since first injection (years) & $12 \cdot 2(5 \cdot 6)$ & $13.7(5.9)$ & $11 \cdot 7(6 \cdot 5)$ & \\
\hline No who injected in last week & $14(78 \%)$ & $76(68 \%)$ & $118(67 \%)$ & \\
\hline Mean (SD) No of injections/month $\dagger$ & $47 \cdot 1(57 \cdot 2)$ & $.29 \cdot 6(33.9)$ & $29.5(36.5)$ & \\
\hline \multicolumn{5}{|l|}{ Main drug injectedt } \\
\hline heroin & $2(11 \%)$ & $18(16 \%)$ & $37(21 \%)$ & \\
\hline cocaine & $3(17 \%)$ & $13(12 \%)$ & $16(9 \%)$ & \\
\hline heroin and cocaine & $11(61 \%)$ & $68(61 \%)$ & $104(59 \%)$ & \\
\hline other (amphetamines or mixture) & $2(11 \%)$ & $13(12 \%)$ & $20(11 \%)$ & \\
\hline \multicolumn{5}{|l|}{$\begin{array}{l}\text { Laboratory results at index visit } \\
\text { (see methods) }\end{array}$} \\
\hline Mean (SD) CD4 cells $/ \mathrm{mm}^{3}$ & $670(390)$ & $450(250)$ & $1000(360)$ & $670(320)$ \\
\hline Mean (SD) anti-CD3 Mab cpm/CD3 $\ddagger$ & $75(84)^{\star}$ & $71(75)$ & $134(119)$ & $151(136)^{\star}$ \\
\hline Mean phytohaemagglutinine $\mathrm{cpm} / \mathrm{CD} 3 \ddagger$ & $796(446)$ & $751(501)$ & $918(455)$ & $702(409)$ \\
\hline
\end{tabular}

${ }^{\star} \mathrm{p}<0.05$ between drug users who seroconverted compared to homosexual men who seroconverted. †In four to six months before index visit. $¥ \mathrm{~T}$ cell function measured after stimulation with anti-CD3 Mab or phytohaemagglutinine expressed as counts per minute per CD $3+$ 'ell.

TABLE II-Number (\%) of subjects reporting clinical symptoms in period preceding index visit

\begin{tabular}{lccc}
\hline & $\begin{array}{c}\text { Intravenous } \\
\text { drug users who } \\
\text { seroconverted } \\
\text { for HIV } \\
(\mathrm{n}=18)\end{array}$ & $\begin{array}{c}\text { Intravenous } \\
\text { drug users } \\
\text { negative for HIV } \\
(\mathrm{n}=177)\end{array}$ & $\begin{array}{c}\text { Homosexual } \\
\text { men who } \\
\text { seroconverted } \\
\text { for HIV } \\
(\mathrm{n}=27)\end{array}$ \\
\hline Symptom & $4(22)$ & $29(16)$ & $8(30)$ \\
Tiredness & $6(33)$ & $46(26)$ & $13(48)$ \\
Fever $\left(>38^{\circ} \mathrm{C}\right)$ & $2(11)$ & $33(19)$ & $5(19)$ \\
Nightsweats & $2(11)$ & $0(0)$ & $7(26)$ \\
Pain with swallowing & $2(11)$ & $15(9)$ & $4(15)$ \\
Headaches & $5(28)^{\star}$ & $16(9)$ & \\
Skin abscesses due to & $5(28)^{\star \star}$ & $3(2)$ & $0(0)$ \\
injecting & $1(6)$ & $0(0)$ & $0(0)$ \\
Bacterial pneumonia & & & \\
Oesophageal candidiasis & & &
\end{tabular}

${ }^{\star} \mathrm{p}=<0.05$ compared with controls (drug users negative and positive for HIV) and homosexual men who seroconverted (Fisher's exact test). $\star \star \mathrm{p}=<0.001$ compared with controls and homosexual men who seroconverted (Fisher's exact test).

TABLE III-Main clinical symptoms of six intravenous drug misusers who seroconverted for HIV in four to six months preceding seroconversion

\begin{tabular}{|c|c|c|c|c|c|}
\hline $\begin{array}{l}\text { Patient } \\
\text { No }\end{array}$ & Sex & Diagnosis & $\begin{array}{l}\text { Admitted to } \\
\text { hospital }\end{array}$ & Culture & $\begin{array}{l}\text { Infiltrate } \\
\text { on } x \text { ray }\end{array}$ \\
\hline 1 & Woman & Pneumonia & Yes & Sputum Haemophilus influenzae & Yes \\
\hline 2 & Woman & Pneumonia & Yes & Negative & Yes \\
\hline 3 & Woman & Pneumonia & Yes & $\begin{array}{l}\text { Sputum Haemophilus influenzae and } \\
\text { Streptococcus pneumonia }\end{array}$ & Yes \\
\hline 4 & Man & Pneumonia & Yes & Negative & Yes \\
\hline $5^{\star}$ & Woman & $\begin{array}{l}\text { Pneumonia, endocarditis, } \\
\text { myelopathy }\end{array}$ & Yes & $\begin{array}{l}\text { Sputum Haemophilus influenzae, } \\
\text { blood Staphylococcus aureus }\end{array}$ & Yes \\
\hline $6^{\star}$ & Woman & Oesophageal candidiasis & No & Candida $†$ & \\
\hline
\end{tabular}

*Initially diagnosed as AIDS, withdrawn in patient 5 .

tCulture from oesophageal biopsy.
TABLE IV-Unadjusted and adjusted multivariate logistic regression analysis in drug users who seroconverted to HIV, drug users positive for $H I V$, and drug users negative for HIV

\begin{tabular}{|c|c|c|}
\hline & $\begin{array}{l}\text { Unadjusted odds ratio } \\
\text { (95\% confidence } \\
\text { interval) }\end{array}$ & $\begin{array}{l}\text { Adjusted odds ratio } \\
\text { (95\% confidence } \\
\text { interval) }\end{array}$ \\
\hline $\begin{array}{l}\text { Drug users positive for HIV } \\
\text { Drug users who seroconverted } \\
\text { Drug users negative for HIV }\end{array}$ & $\begin{array}{l}1 \\
3.92(1.16 \text { to } 13 \cdot 27) \\
0.18(0.05 \text { to } 0.66)\end{array}$ & $\begin{array}{l}1 \\
4.89(1.21 \text { to } 19.86) \\
0.13(0.03 \text { to } 0.52)\end{array}$ \\
\hline
\end{tabular}

^Adjusted for sex, age, steady housing, season in which participant suffered from pneumonia, years since first injection, frequency of injecting, and drug mainly injected (heroin, cocaine, or mixture of both)

symptoms accompanying seroconversion, such as fever, tiredness, pain accompanying swallowing, headaches, and nightsweats, were not reported significantly more often by the drug users who seroconverted compared to controls for HIV. Skin abscesses due to injecting, however, were reported significantly more often by drug users who seroconverted compared to controls negative for HIV.

Pneumonia was the clinical symptom most strongly associated with seroconversion among drug users. As described above five out of $18(28 \%)$ injecting drug users who seroconverted reported pneumonia and all were admitted to hospital (table III). In contrast none of the 27 homosexual men who seroconverted $(p=0.007$ compared to drug users who seroconverted) and only three of the $177(2 \%)$ of the drug users negative for HIV ( $p=0.0002$ compared to drug users who seroconverted) reported pneumonia in the preceding period. None of the three drug users negative for HIV with pneumonia was admitted to hospital. We considered subjects positive for HIV as controls in the comparison of pneumonia because the incidence of pneumonia among drug users positive for HIV was shown to be significantly higher compared to drug users negative for HIV. ${ }^{4}$ Ten out of $112(9 \%)$ controls positive for HIV developed pneumonia of whom three were admitted to hospital ( $\mathrm{p}=0.038$ compared to drug users who seroconverted).

To study whether demographic, social, drug related, or immunological factors influenced the development of bacterial pneumonia among drug users, the characteristics of drug users who seroconverted but did or did not develop bacterial pneumonia were compared. The immunological data of the index visit (first HIV positive visit of the seroconverters), the visit preceding the index visit (four to six months before), and the visit four to six months after the index visit were compared. No variable was univariately related to a history of bacterial pneumonia among the drug users who seroconverted (data not shown).

The results of the multivariate logistic regression analysis in the total group of intravenous drug misusers (seroconverters and HIV negative and HIV positive subjects) are shown in table IV. The unadjusted odds ratio of drug users who seroconverted to acquire bacterial pneumonia was 3.92 compared with drug users positive for HIV. The odds ratio adjusted for sex, age, steady housing, season in which the participant suffered from pneumonia, years since first injection, frequency of injecting, and drug mainly injected (heroin, cocaine, or a mixture of both) was 4.89 . The odds ratio for drug users negative for HIV to acquire bacterial pneumonia compared with those positive for HIV was 0.18 unadjusted and $0 \cdot 13$ adjusted.

\section{Discussion}

Our prospective study has shown that serious clinical symptoms associated with seroconversion for HIV among intravenous drug misusers occur often. Of the 18 drug users who seroconverted, five were admitted to hospital for bacterial pneumonia and one woman was 
treated as an outpatient for oesophageal candidiasis. In total six out of $18(33 \%)$ of the drug users who seroconverted in our cohort had serious manifestations associated with seroconversion. For comparison, of the 27 homosexual men who seroconverted none had suffered from bacterial pneumonia, nor had any participant been treated for complications of his HIV infection. Moreover, from an additional 90 homosexual men who seroconverted between the start of the homosexual cohort in October 1984 and the start of the present study in April 1989, none suffered from pneumonia in the six months before seroconversion.

To our knowledge this is the first prospective study that has shown that bacterial pneumonia is associated with HIV seroconversion among intravenous drug misusers. Self selection among the drug users who seroconverted may have biased our results. If the subjects with pneumonia were more likely to return for follow up visits than those without this could have resulted in an overestimation of the incidence of bacterial pneumonia among the drug users who seroconverted. Among the drug users who acted as controls and remained negative for HIV this selection bias would, however, also exist, and therefore the odds ratio for drug users who seroconverted to acquire bacterial pneumonia is likely to be unaffected. Owing to small numbers, however, the power to detect potential confounding in the relation between pneumonia and seroconversion is limited.

The immunological suppression associated with seroconversion is probably an important factor responsible for the increased susceptibility to bacterial pneumonia among drug users who seroconvert. Whether those with pneumonia were more immunocompromised than similar subjects without pneumonia is unknown. We could not detect a significant immunological difference between drug users who seroconverted with bacterial pneumonia and those without, but owing to the long sampling interval the lowest CD4 counts were not necessarily measured.

There may be several reasons why seroconversion seems to be associated with bacterial pneumonia only among intravenous drug users and not among homosexual men. Historically drug users are known to suffer more often from bacterial infections such as pneumonia, ${ }^{61112}$ and this observation agrees with our results and those from a previous study of our cohort. ${ }^{14}$ Several factors such as tobacco smoking, heroin smoking, cannabis use, asthma, bronchitis, heavy alcohol use, malnourishment, and bad social conditions resulting in poor housing and crowding are known to predispose to bacterial pneumonia. Many of these predisposing factors are observed more often among drug users than among homosexual men.

In a previous study we have shown that asymptomatic drug users positive for HIV have a nearly fourfold increased risk of acquiring bacterial pneumonia compared with drug users negative for HIV. ${ }^{4}$ This is in contrast to homosexual men positive for HIV who, in general, suffer from bacterial pneumonia more commonly only in the advanced stages of HIV disease..$^{13}{ }^{14}$ Altogether we found a pattern that indicated a moderately increased incidence of pneumonia among drug users negative for HIV caused by predisposing (and possibly immunological) factors. The strongly increased incidence among drug users who seroconverted is probably due to the temporary immuno- logical depression associated with seroconversion. The risk of bacterial pneumonia among symptomatic drug users positive for HIV is significantly increased compared to those negative for HIV. Skin abscesses due to injecting were reported more often by drug users who seroconverted than by controls but the selection of seroconverters who had probably used infected injecting equipment may have biased this result.

We also compared minor clinical symptoms such as tiredness, fever, nightsweats, pain on swallowing, and headaches between drug users who seroconverted and controls. None of these clinical symptoms, which have been recognised as symptoms of primary HIV infection, differed between drug users who seroconverted and those who were negative for HIV. Among drug users many of these symptoms may be caused by the drugs used, withdrawal of drugs, or, alternatively, symptoms may be suppressed by the use of drugs.

We conclude that among intravenous drug misusers seroconversion for HIV is significantly associated with bacterial pneumonia. When a drug user previously negative for HIV is admitted to hospital for bacterial pneumonia serological tests should be performed to detect possible seroconversion for HIV.

We thank B Frölich, B Scheeringa-Troost, R Lopes Diaz, and Nel Albrecht van Lent for interviewing; Professor Goudsmit and M Bakker for virological tests; F Miedema and $M$ Roos for immunological testing; $H$ Fennema and R Keet for physical examination; $\mathrm{H}$ van Haastrecht for data management and critical comment; and $\mathrm{M}$ ter Pelle for preparation of the manuscript.

This study was supported by the Netherlands Foundation for Preventive Medicine (grant No 28-1258).

1 Jong de MD, Hulsebosch HJ, Lange JMA. Clinical, virological and immunological features of primary HIV-1 infection. Genitourin Med 1991;67:367-73.

2 Pena JM, Martinéz-López MA, Arnalich F, Barbado FJ, Vazquez JJ. Oesophageal candidiasis associated with acute infection due to human immunodeficiency virus: case report and review. Rev Infect Dis 1991;13: $872-5$.

3 Tindall B, Hing M, Edwards P, Barnes T, Mackie A, Cooper DA. Severe clinical manifestations of primary HIV infection. AIDS 1989;3:747-9.

4 Mientjes GH, Ameijden van EJ, Hoek van den JAR, Coutinho RA. Increasing morbidity without rise in non-AIDS mortality among HIV-infected intramorbidity without rise in non-AIDS mortality among
venous drug users in Amsterdam. AIDS 1992;6:207-12.

5 Selwyn PA, Hartel D, Wasserman W, Drucker E. Impact of the AIDS epidemic on morbidity and mortality among intravenous drug users in New York City methadone maintenance program. Am $f$ Public Health 1989;79:1358-62

6 Louria DB, Hensle T, Rose J. The major medical complications of heroin addiction. Ann Intern Med 1967;67:1-22.

7 Mientjes GH, Miedema F, Ameijden van EJ, Hoek van den JAR, Schellekens PTA, Roos MTh, et al. Frequent injecting impairs lymphocyte reactivity in HIV-positive and HIV-negative drug users. AIDS 1991;5:35-41.

8 Hoek van den JAR, Coutinho RA, Haastrecht van HJA, Zadelhoff van AW, Goudsmit J. Prevalence and risk factors of HIV infections among drug users and drug-using prostitutes in Amsterdam. AIDS 1988;2:55-60.

9 Wolf de F, Lange JMA, Houweling JTM, Mulder JW, Beemster J, Schellekens PTA. Appearance of predictors of disease progression in Schellekens PTA. Appearance of predictors of disese
relation to the development of AIDS. AIDS 1989;3:235-7

10 Bloemema E, Roos MTL, Heijst van IL, Vossen JM, Schellekens PTA. Whole blood lymphocyte cultures. f Immunol Meth 1989;122:161-7.

11 Manos GE, Deutekom van H, Peerbooms PGH, Coutinho RA. Community acquired pneumonia in drug abusers in Amsterdam. Lancet 1990;336: 939-40.

12 Scheidegger C, Zimmerli W. Infectious complications in drug addicts: seven-year review of 269 hospitalized narcotics abusers in Switzerland. Rev Infect Dis 1989;11:486-93.

13 Parkin JM, Helbert M, Hughes CL, Pinching AJ. Immunoglobulin G subclass deficiency and susceptibility to pyogenic infections in patients with AIDSrelated complex and AIDS. AIDS 1989;3:37-9.

14 Witt DJ, Craven DE, McCabe WR. Bacterial infections in adult patients with the acquired immune deficiency syndrome (AIDS) and AIDS-related complex. Ann f Med 1987;82:900-6.

(Accepted 20 November 1992) 